\title{
Eupolyphaga sinensis Walker demonstrates angiogenic activity and inhibits A549 cell growth by targeting the KDR signaling pathway
}

\author{
BINGLING DAI，JUNPENG QI，RUI LIU and YANMIN ZHANG \\ School of Pharmacy, Health Science Center, Xi'an Jiaotong University, Xi'an, Shaanxi 710061, P.R. China
}

Received October 30, 2013; Accepted December 12, 2013

DOI: $10.3892 / \mathrm{mmr} .2014 .2387$

\begin{abstract}
Eupolyphaga sinensis Walker has been reported to have anticoagulation, antithrombotic, liver protective and antitumor effects. In the present study, the inhibitory effects on proliferation of A549 human non-small cell lung cancer cells and the underlying mechanisms were examined. Firstly, three solvents, $70 \%$ ethanol, distilled water and $95 \%$ ethanol, were used to extract Eupolyphaga sinensis Walker. The MTT assay results demonstrated that the $70 \%$ ethanol extract more potently reduced the growth of A549 cells and it was therefore adopted in the subsequent experiments. Eupolyphaga sinensis Walker $70 \%$ ethanol extract significantly inhibited A549 cell migration in a time- and dose-dependent manner and inhibited human umbilical vein endothelial cell proliferation, migration and tube formation. Furthermore, Eupolyphaga sinensis Walker $70 \%$ ethanol extract effectively inhibited blood vessel formation in the established tissue model for angiogenesis. In addition, Eupolyphaga sinensis Walker $70 \%$ ethanol extract was demonstrated to inhibit the autophosphorylation of KDR, and downregulate the subsequent activation of AKT and extracellular signal regulated kinase (ERK)1/2 in A549 cells. In conclusion, these findings demonstrated that the antitumor mechanism of Eupolyphaga sinensis Walker $70 \%$ ethanol extract was through inhibiting angiogenesis. It functioned by interrupting the autophosphorylation of KDR and subsequently, AKT and ERK1/2.
\end{abstract}

\section{Introduction}

In the early 1970s, Folkman first proposed that tumors depend on the generation of new blood vessels, a process known as angiogenesis (1). When a tumor grows beyond 1-2 $\mathrm{mm}$ in size, it requires new blood vessels to supply its nutritional requirements (2). Angiogenesis is a prerequisite for the growth and

Correspondence to: Professor Yanmin Zhang, School of Pharmacy, Health Science Center, Xi'an Jiaotong University, 76 Yanta West Street, Xi'an, Shaanxi 710061, P.R. China

E-mail: zhang2008@mail.xjtu.edu.cn

Key words: Eupolyphaga sinensis Walker, vascular endothelial growth factor, A549 cells, human umbilical vein endothelial cells metastasis of solid tumors $(3,4)$. It is regulated by a number of proteins, including vascular endothelial growth factor (VEGF), acidic and basic fibroblast growth factors, angiogenin, epidermal growth factor, scatter factor and placental growth factor (5). Among them, VEGF has been confirmed as highly important in angiogenesis in a number of preclinical and clinical studies $(6,7)$. VEGF binds to its receptors VEGFR-1 and KDR, inducing the activation of KDR, and then regulating endothelial cell proliferation, migration and differentiation to induce the growth of new blood vessels (8). There are numerous signaling cascades involved in the VEGF/VEGFR pathway, among them phosphatidylinositol 3-kinase (PI3K)/AKT and extracellular signal-regulated kinase-mitogen-activated protein kinases (ERK-MAPK) are highly important in the regulation of cellular proliferation, migration and angiogenesis (9). VEGF is expressed in the majority of tumor types, often at a significantly increased levels (10). The expression of VEGF has been linked to tumor growth, angiogenesis and metastasis and its overexpression has been associated with a poor prognosis in non-small cell lung cancer (NSCLC) (11).

Previously, a number of anti-angiogenic drugs have been licensed or investigated in various clinical trials (12). All currently approved anti-angiogenic agents consist of monoclonal antibodies (mAbs) targeting specific proangiogenic factors (13) and synthetic tyrosine kinase inhibitors targeting multiple proangiogenic factors (14). These anti-angiogenic agents, used in combination with conventional chemotherapeutic regimens, were shown to prolong patient survival (15). Therefore, it is important to investigate antitumor activity on the basis of inhibiting tumor angiogenesis (16).

Eupolyphaga sinensis Walker is one of the numerous insects that are commonly used in Chinese traditional medicines and as a source of food (17). In long term practice, Eupolyphaga sinensis Walker has been used to treat numerous different diseases, including ecchymoma, posttraumatic wound healing, hepatic fibrosis and cancer (18). However, the antitumor effect of Eupolyphaga sinensis Walker remains to be elucidated. In the present study, its effect on A549 human NSCLC cells and the potential antiangiogenic mechanisms were examined.

\section{Materials and methods}

Reagents. RPMI-1640 and F-12K were purchased from Gibco-BRL (Carlsbad, CA, USA). Trypsin was obtained from 
Amresco (Solon, OH, USA). Fibrinogen from bovine plasma was purchased from Sigma (St. Louis, MO, USA) and thrombin was obtained from Guoao Pharmaceutical (Changchun, China). Anti-phospho-KDR rabbit $\mathrm{mAb}$ was from Upstate Biotechnology (Lake Placid, NY, USA); -AKT was obtained from Epitomics, Inc., (Burlingame, CA, USA); -phospho-AKT rabbit mAb, -p44/42 MAPK (ERK1/2) and -phospho-p44/42 MAPK (ERK1/2) rabbit $\mathrm{mAb}$ were from Cell Signaling Technology, Inc.(Danvers, MA, USA). Rabbit anti-GAPDH was purchased from Pierce Biotechnology, Inc. (Rockford, IL, USA). KDR and fluorescein isothiocyanate-goat anti-rabbit IgG $(\mathrm{H}+\mathrm{L})$ was purchased from Protein Tech Group Inc. (Chicago, IL, USA). Histostain TM-Plus kits and a DAB kit were purchased from ZSGB-BIO (Beijing, China). Rabbit anti-mouse $\mathrm{IgG}$, goat anti-rabbit $\mathrm{IgG}$, a bicinchoninic acid (BCA) protein assay reagent kit and an enhanced chemiluminescent (ECL) plus reagent kit were obtained from Pierce Biotechnology, Inc.

Preparation of Eupolyphaga sinensis Walker ethanol and water extracts. The raw material used in the study was commercially available as dry matter, which was purchased from Yishengtang Pharmacy (Xi'an, China). The $70 \%$ ethanol extract was obtained as previously described (19). The stock solution was further diluted with RPMI-1640 medium immediately prior to use. The water solution extraction from the raw powder was obtained in the same way.

Another extraction method used was as follows: The raw material was crushed and soaked in $95 \%$ ethanol overnight and then refluxed gently in ten volumes of $95 \%$ ethanol (v/w) for $1 \mathrm{~h}$, and then extracted three times. Following cooling, the extracting solutions were merged and filtered to obtain a yellow oily liquid. The solvent was then evaporated under reduced pressure and concentrated to $1 \mathrm{~g} / \mathrm{ml}$ (equivalent to raw material). The suspension was then centrifuged (600 g, $20 \mathrm{~min}$ ) and filtered using a $0.22-\mu \mathrm{m}$ microporous membrane (Shanghai Xinya Purifier Devices Factory, Shanghai, China). The stock solution was stored at $4^{\circ} \mathrm{C}$ and further diluted with serum-free IMDM immediately prior to use.

Cell culture. The A549 human NSCLC cell line was purchased from the Shanghai Institute of Cell Biology in the Chinese Academy of Sciences (Shanghai, China). The A549 cells were cultured in RPMI-1640 medium supplemented with $10 \%$ fetal bovine serum (FBS) and incubated at $37^{\circ} \mathrm{C}$ in a $5 \% \mathrm{CO}_{2}$ atmosphere. Human umbilical vein endothelial cells (HUVECs) from the American Type Culture Collection (Manassas, VA, USA) was cultured in F-12K media supplemented with $0.1 \mathrm{mg} / \mathrm{ml}$ heparin, $0.5 \mathrm{mg} / \mathrm{ml}$ endothelial cell growth supplement and $10 \% \mathrm{FBS}$. The cells were incubated at $37^{\circ} \mathrm{C}$ in a $5 \%$ $\mathrm{CO}_{2}$ atmosphere.

Mice. Kunming SPF mice (age, 4-6 weeks; weight, 18-22 g) were provided by the Animal Research Center of Xi'an Jiao Tong University (Xi'an, China). The mice were maintained under laminar air flow conditions with a $12 \mathrm{~h}$ light (6:00-18:00)/12 h dark (18:00-6:00) cycle. Laboratory food and water were freely available. The animal care procedures were in accordance with the National Institute of Health guidelines and the Animal Research Committee of Xi'an Jiao Tong University (Xi'an, China).
Cell viability assay. The cell viability was assessed by the tetrazolium-based assay (MTT assay). Exponentially growing A549 cells were plated onto the 96-well plate (in RPMI-1640 with $10 \%$ FBS) and cultivated for $24 \mathrm{~h}$. A series of different concentrations of $70 \%$ ethanol extract, water extract and $95 \%$ ethanol extract in serum-free RPMI-1640 medium were then added to the 96-well plate for $48 \mathrm{~h}$. Following $48 \mathrm{~h}, 180 \mu \mathrm{l}$ serum-free medium and $20 \mu \mathrm{l}$ MTT solution $(5 \mathrm{mg} / \mathrm{ml})$ were added to each well. The plates were incubated at $37^{\circ} \mathrm{C}$ for $4 \mathrm{~h}$. The supernatants were then removed and the formazan crystals were dissolved with $150 \mu \mathrm{l}$ dimethyl sulfoxide and shaken thoroughly for $15 \mathrm{~min}$ on an orbital shaker (TS-100; Kylin-Bell Lab Instruments Co., Ltd., Jiangsu, China) prior to measurement. HUVECs were treated with $70 \%$ ethanol extract for $48 \mathrm{~h}$ followed with the above experimental method. The absorbance was measured at $490 \mathrm{~nm}$ in a microplate reader (Bio-Rad Laboratories, Hercules, CA, USA). The results are expressed as a percentage of the cell inhibition ratio. Percentage of proliferation ratio $=\left(\mathrm{OD}_{\text {treatment group }}-\mathrm{OD}_{\text {blank }}\right.$ group $) /\left(\mathrm{OD}_{\text {control group }}-\mathrm{OD}_{\text {blank group }}\right) \times 100 \%$. The experiments were performed in triplicate.

Wound healing assay. HUVEC and A549 cells were seeded onto the 12 -well plate $\left(6 \times 10^{5}\right.$ cells $\left./ \mathrm{ml}\right)$ and cultivated to $\sim 80 \%$ confluence overnight. The wounds were made the following day by scratching the cells with pipette tips (100-200 $\mu \mathrm{l})$. The HUVEC and A549 cells were then treated with $70 \%$ ethanol extract at various concentrations $(0,0.075,0.15,0.3 \mathrm{mg} / \mathrm{ml})$ for different times to allow the cells to migrate into the scratched area. The migration of cells was visualized at time 0 (right after the wound was scratched) and 24, 48 and $72 \mathrm{~h}$ following $70 \%$ ethanol extract treatments.

Tube formation assay. A 48-well plate was coated with $200 \mu \mathrm{l} /$ well lypolymerized fibrinogen (diluted in serum-free RPMI-1640 to $3 \mathrm{mg} / \mathrm{ml}$ ) and $5 \mu \mathrm{l} /$ well thrombin $(50 \mathrm{U} / \mathrm{ml})$, and incubated at $37^{\circ} \mathrm{C}$ for $30 \mathrm{~min}$ to form a gel layer. Following gel formation, $1 \times 10^{5}$ HUVECs were seeded into each well in $500 \mu \mathrm{l}$ of $10 \%$ FBS-containing RPMI-1640 medium and various concentrations of $70 \%$ ethanol extract $(0,0.075$, 0.15 and $0.3 \mathrm{mg} / \mathrm{ml}$ ) were applied to each well for $24 \mathrm{~h}$. The images of the formation of capillary tubes were then captured randomly under a microscope (DM505; Nikon Co., Ltd., Otawara, Japan). The length of the tubes was measured with using Image-Pro Plus software (Image-Pro Plus 5.1; Media Cybernetics, Inc., Rockville, MD, USA), with three images from separate experiments for each data point. The inhibition rate of tube formation was calculated as: [1-(tube lengthtreated $/$ tube length control $\left._{1}\right)$ x 100.

Inhibition of angiogenesis in lung tissue. The mice (weight, 15-18 g) were soaked in $75 \%$ alcohol for $5 \mathrm{~min}$ after they had been sacrificed by cervical dislocation. Subsequently, lung tissue was cultured as previously described (20). The second layer of fibrin matrices with thrombin were placed on the lung tissue to form a sandwich structure. Following consolidation, $200 \mu \mathrm{l} /$ well RPMI-1640 medium containing different concentrations of $70 \%$ ethanol extract $(0,0.075,0.15$ and $0.3 \mathrm{mg} / \mathrm{ml})$ was added to the 48 -well plate. The 48 -well plate was incubated at $37^{\circ} \mathrm{C}$ in a $5 \% \mathrm{CO}_{2}$ atmosphere. The sprouting vessels 

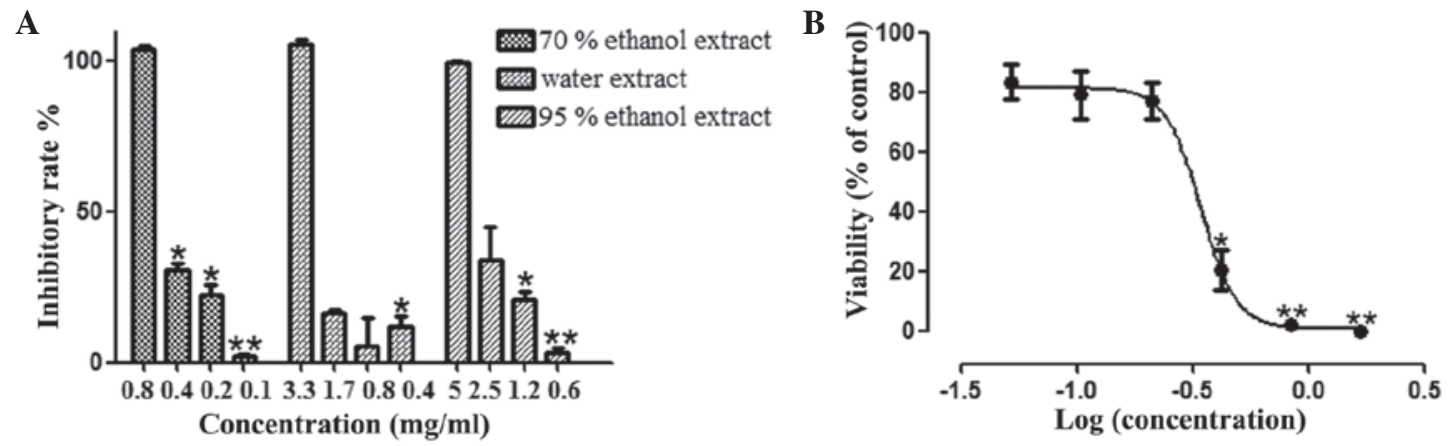

Figure 1. Eupolyphaga sinensis Walker extract inhibited A549 cell growth and Eupolyphaga sinensis Walker 70\% extract inhibited HUVEC growth in vitro. (A) A549 cells were treated with 70\% ethanol extract, distilled water extract and 95\% ethanol extract for $48 \mathrm{~h}$. (B) HUVECs were treated with $70 \%$ ethanol extract at the indicated concentration for $48 \mathrm{~h}$. Data are expressed as the mean \pm standard error of the mean ( $\mathrm{n}=2)$. ${ }^{*} \mathrm{P}<0.05$ and ${ }^{* *} \mathrm{P}<0.01$ compared with the control group. HUVECs, human umbilical vein endothelial cells.

were observed at the 5 th day post treatment, the total number of microvessels were counted under a microscope and the mean values \pm standard error of the mean were calculated. These experiments were conducted on three separate mice and repeated three times.

Western blot analysis. The A549 cells treated with $70 \%$ ethanol extract $(0,0.075,0.15,0.3 \mathrm{mg} / \mathrm{ml})$ for $48 \mathrm{~h}$ were extracted with radioimmunoprecipitation assay buffer on ice for $30 \mathrm{~min}$. The insoluble protein lysate was removed by centrifugation at $9,300 \mathrm{~g}$ for $10 \mathrm{~min}$ at $4^{\circ} \mathrm{C}$. The protein concentration was determined by the BCA Protein Quantification kit according to the manufacturer's instructions. The cell lysates were denatured by boiling with $5 \mathrm{X}$ reducing sample buffer for 5 min and run on SDS-PAGE gel. Following electrophoresis, the separated proteins were then transferred to polyvinylidene fluoride membrane and blocked with 5\% non-fat milk in Tris-buffered saline Tween-20 (TBST) buffer for $2 \mathrm{~h}$ at room temperature with continuous agitation. The membranes were then incubated with specific primary antibodies, including anti-KDR, anti-p-KDR (1:500 dilution), anti-AKT, anti-p-AKT, anti-ERK1/2, anti p-ERK1/2 and anti-GAPDH (1:1000 dilution) overnight at $4^{\circ} \mathrm{C}$ followed by washing and incubated with secondary antibodies at a dilution of 1:20,000 in TBST buffer for $2 \mathrm{~h}$ at $37^{\circ} \mathrm{C}$. The membranes were then washed with TBST buffer for 10 min 3 times and developed with an ECL kit.

Statistical analysis. All data were expressed as the mean \pm standard error of the mean. Statistical analysis was performed using the statistical software SPSS 18.0 (SPSS, Inc., Chicago, IL, USA) and analysis of variance was used to analyze the statistical differences between groups under different conditions. $\mathrm{P}<0.05$ was considered to indicate a statistically significant difference.

\section{Results}

Effect of Eupolyphaga sinensis Walker extracts on the proliferation of A549 cells. Three solvents were used in the present study, $70 \%$ ethanol, distilled water and $95 \%$ ethanol, to extract Eupolyphaga sinensis Walker. Firstly, it was investigated whether the three types of extract had antiproliferative effects against human lung cancer cells using the MTT assay (an antiproliferative assay) to measure A549 cell viability. As demonstrated in Fig. 1A, the 70\% ethanol extract and 95\% ethanol extract decreased cell viability in a dose-dependent manner, but the $70 \%$ ethanol extract demonstrated notably stronger inhibition. The IC50 of the 70\% ethanol extract, water extract and $95 \%$ ethanol extract were $0.27,1.13$ and $1.64 \mathrm{mg} / \mathrm{ml}$, respectively. Therefore, the $70 \%$ ethanol extract was used for the subsequent experiments.

Effect of the $70 \%$ ethanol extract on proliferation and migration of HUVECs. It was also determined whether the $70 \%$ ethanol extract was able to exert any effect on the endothelial cells. The effect of $70 \%$ ethanol extract on the proliferation of HUVECs was determined at $48 \mathrm{~h}$. The $70 \%$ ethanol extract inhibited the proliferation of HUVECs in a dose-dependent manner and the IC50 value of 70\% ethanol extract on HUVECs was $0.34 \mathrm{mg} / \mathrm{ml}$ (Fig. 1B). Endothelial cell migration is an important process for angiogenesis. The migration of HUVECs was observed using a wound healing assay. Compared with the control group, a large number of HUVECs migrated to fill the scratched area at $24 \mathrm{~h}$. The $70 \%$ ethanol extract significantly inhibited the migration of HUVECs at $0.075,0.15$ and $0.3 \mathrm{mg} / \mathrm{ml}$ concentrations (Fig. 2).

Effect of HMQ1611 on tube formation of HUVECs. Tube formation is a highly important procedure during which resting endothelial cells eventually differentiate into new vessels. An assay was utilized to investigate the inhibitory effect of $70 \%$ ethanol extract on angiogenesis in vitro. A total of $1 \times 10^{5}$ HUVECs with or without different concentrations of the $70 \%$ ethanol extract were added to matrigel to form an extensive and enclosed network of tubes within 24 h. Fig. 3 demonstrates that treatment with $70 \%$ ethanol extract $(0.075,0.15,0.3 \mathrm{mg} / \mathrm{ml})$ inhibited the tube formation in a dose-dependent manner. The inhibitory percentages for concentrations of $0.3,0.15$ and $0.075 \mathrm{mg} / \mathrm{ml}$ were $53.15,33.08$ and $15.45 \%$ respectively.

Effect of $70 \%$ ethanol extract on the migration of A549 cells. The ability of $70 \%$ ethanol extract to inhibit the migration of A549 cells by a wound healing assay. Scratched A549 


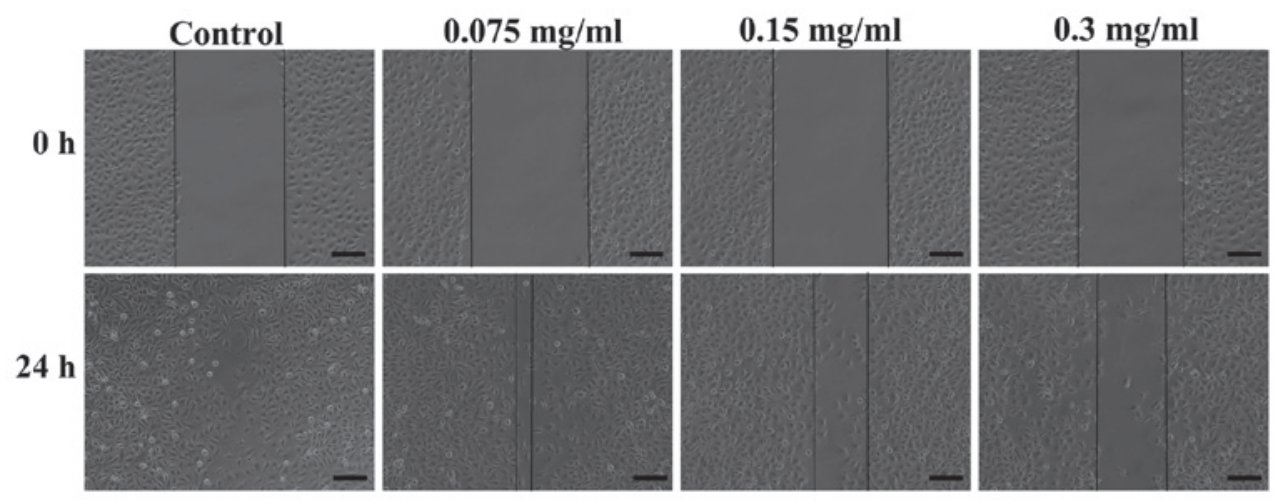

Figure 2. Eupolyphaga sinensis Walker 70\% ethanol extract inhibited HUVEC cell migration. HUVEC cell migration decreased following treatment with $70 \%$ ethanol extract at $24 \mathrm{~h}$, scale bar, $100 \mu \mathrm{m}$. HUVECs, human umbilical vein endothelial cells.

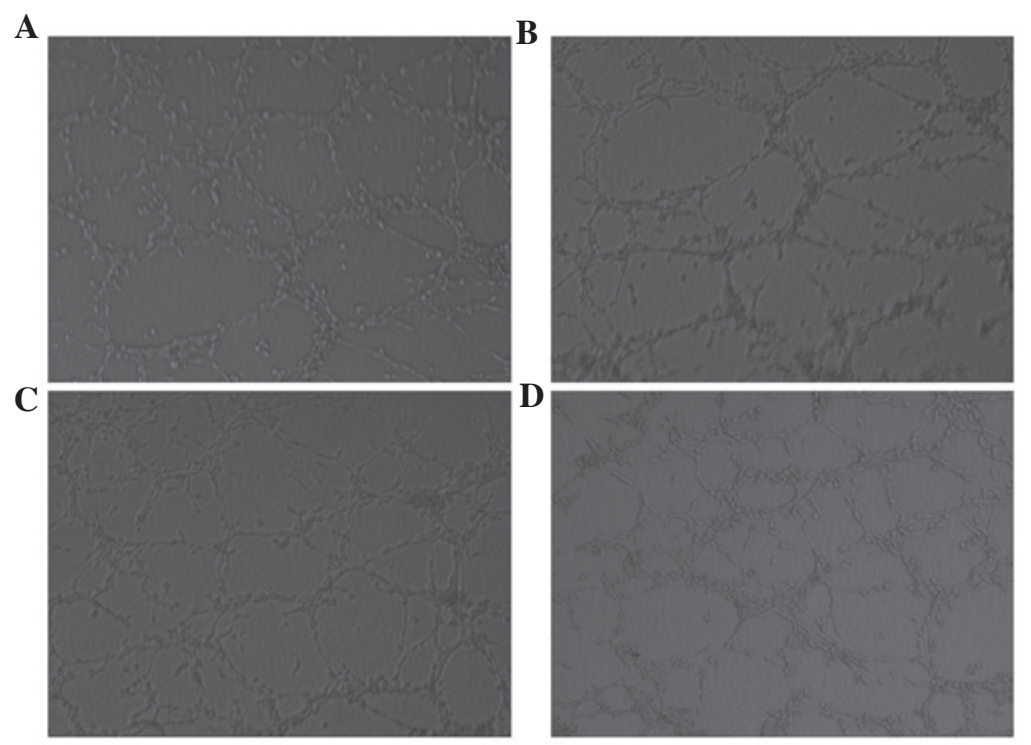

$\mathbf{E}$

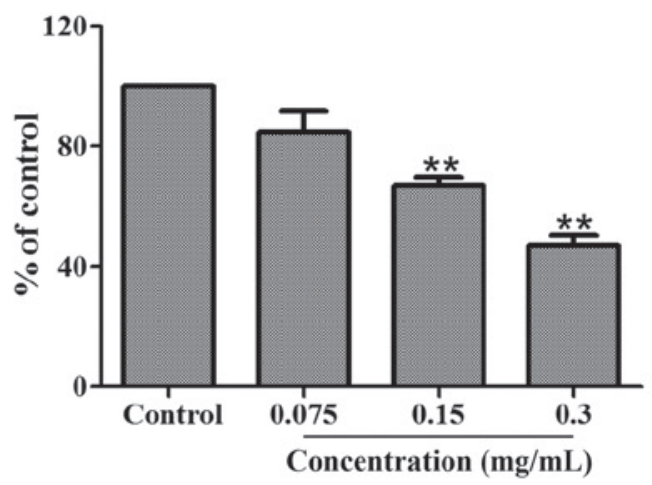

Figure 3. Eupolyphaga sinensis Walker 70\% ethanol extract inhibited HUVEC cell tube formation. Tube formation of HUVEC cells treated with the vehicle (A) or Eupolyphaga sinensis Walker 70\% ethanol extract at the concentrations of (B) $0.075 \mathrm{mg} / \mathrm{ml}$, (C) $0.15 \mathrm{mg} / \mathrm{ml}$ and (D) $0.3 \mathrm{mg} / \mathrm{ml}$ (scale bar, $100 \mu \mathrm{m}$ ). (E) Quantification data of tube formation inhibition following treatment with 70\% ethanol extract. Values are expressed as the mean \pm standard error of the mean $(n=3) .{ }^{* *} \mathrm{P}<0.01$ vs. the control group. HUVECs, human umbilical vein endothelial cells.

cells were treated with $70 \%$ ethanol extract $(0,0.075,0.15$ and $0.3 \mathrm{mg} / \mathrm{ml}$ ) for 24,48 and $72 \mathrm{~h}$. The results revealed that in the absence of $70 \%$ ethanol extract, the cells migrated within $72 \mathrm{~h}$ to fill the scratched area, but the non-cytotoxic treatment of $70 \%$ ethanol extract significantly prevented this migration in 24, 48 and $72 \mathrm{~h}$ during the wound healing assay of A549 cells (Fig. 4). Furthermore, this inhibition occurred in a dose- and time-dependent manner.

Effect of $70 \%$ ethanol extract on the angiogenesis in the lung tissue model. The lung tissue model was established to imitate angiogenesis in vivo. The new vessels grew after the lung tissue was cultured on the 'fibrinogen sandwich structure' for five days. As demonstrated in Fig. 5, 70\% ethanol extract evidently inhibited the formation of new blood vessels compared with the control group. The quantitative data of the number and length of blood vessels indicated that $70 \%$ ethanol extract significantly reduced vascularization of the lung tissue at concentration of $0.075,0.15$ and $0.3 \mathrm{mg} / \mathrm{ml}$, and exhibited this effect in a dose-dependent manner.
Effect of $70 \%$ ethanol extract on the VEGFR signaling pathway in A549 cells. The effect of $70 \%$ ethanol extract on the VEGFR signaling pathway was also determined. The cell lysates were subjected to western blot analysis incubated with various antibodies, including anti-KDR, anti-p-KDR, anti-AKT, anti-p-AKT, anti-ERK1/2, anti-p-ERK1/2 and anti-GAPDH antibodies. As revealed in Fig. 6, treatment with $70 \%$ ethanol extract significantly downregulated the phosphorylation of VEGFR expression. Simultaneously, AKT phosphorylation was significantly inhibited by $70 \%$ ethanol extract treatment in A549 cells. Consistently with the inhibition of AKT activity, the phosphorylation of ERK1/2 was also reduced.

\section{Discussion}

Eupolyphaga sinensis Walker is a traditional Chinese medicine, which has been demonstrated to have anticancer effects. However, the exact molecular mechanisms underlying the antitumor effect of Eupolyphaga sinensis Walker remain unclear. In the present study, the inhibitory effect of 


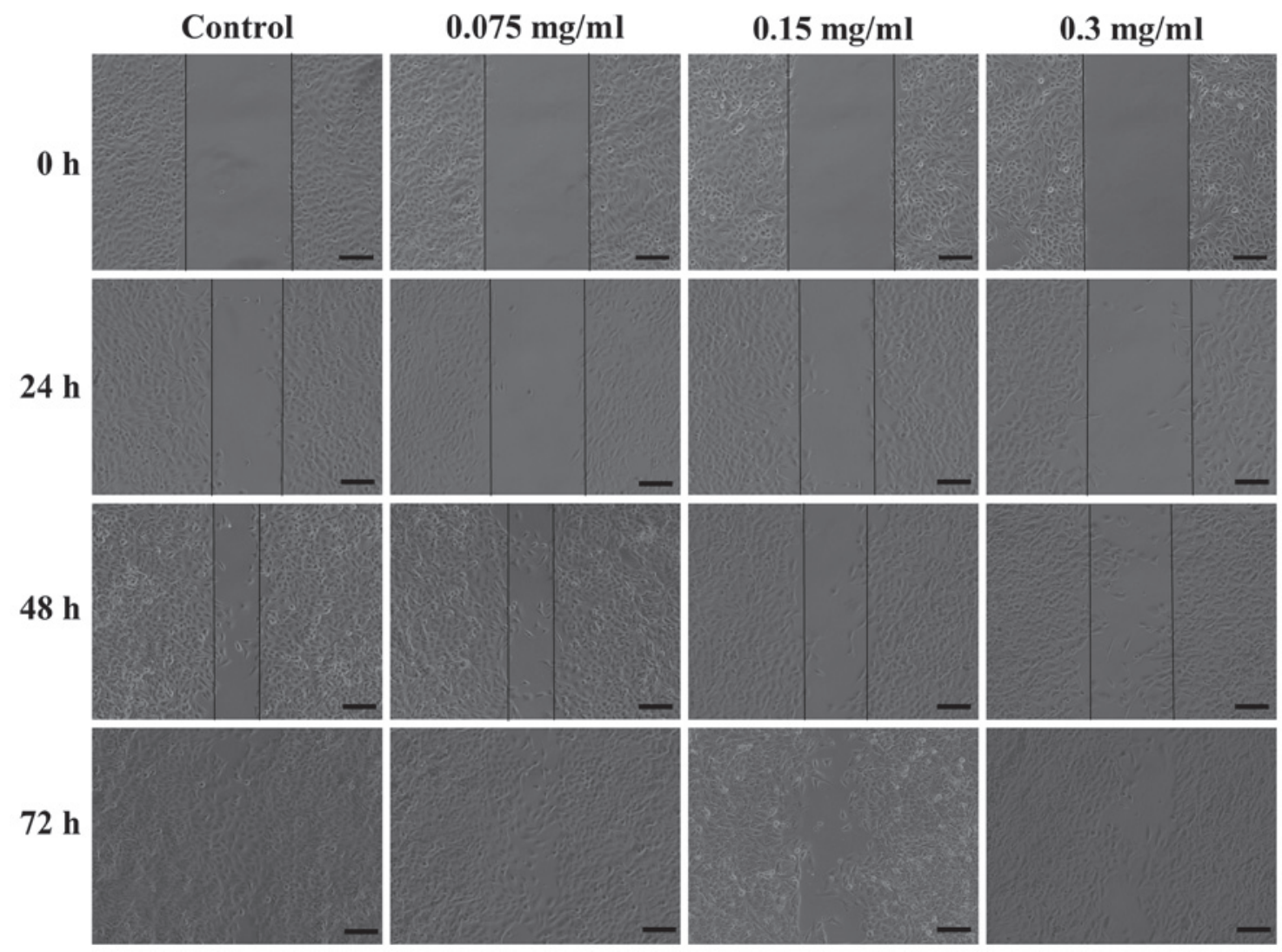

Figure 4. Eupolyphaga sinensis Walker 70\% ethanol extract inhibited migration of A549 cells. A549 cells treated with $70 \%$ ethanol extract exhibited decreased migration at 24, 48 and $72 \mathrm{~h}$ compared with control (scale bar, $100 \mu \mathrm{m}$ ).
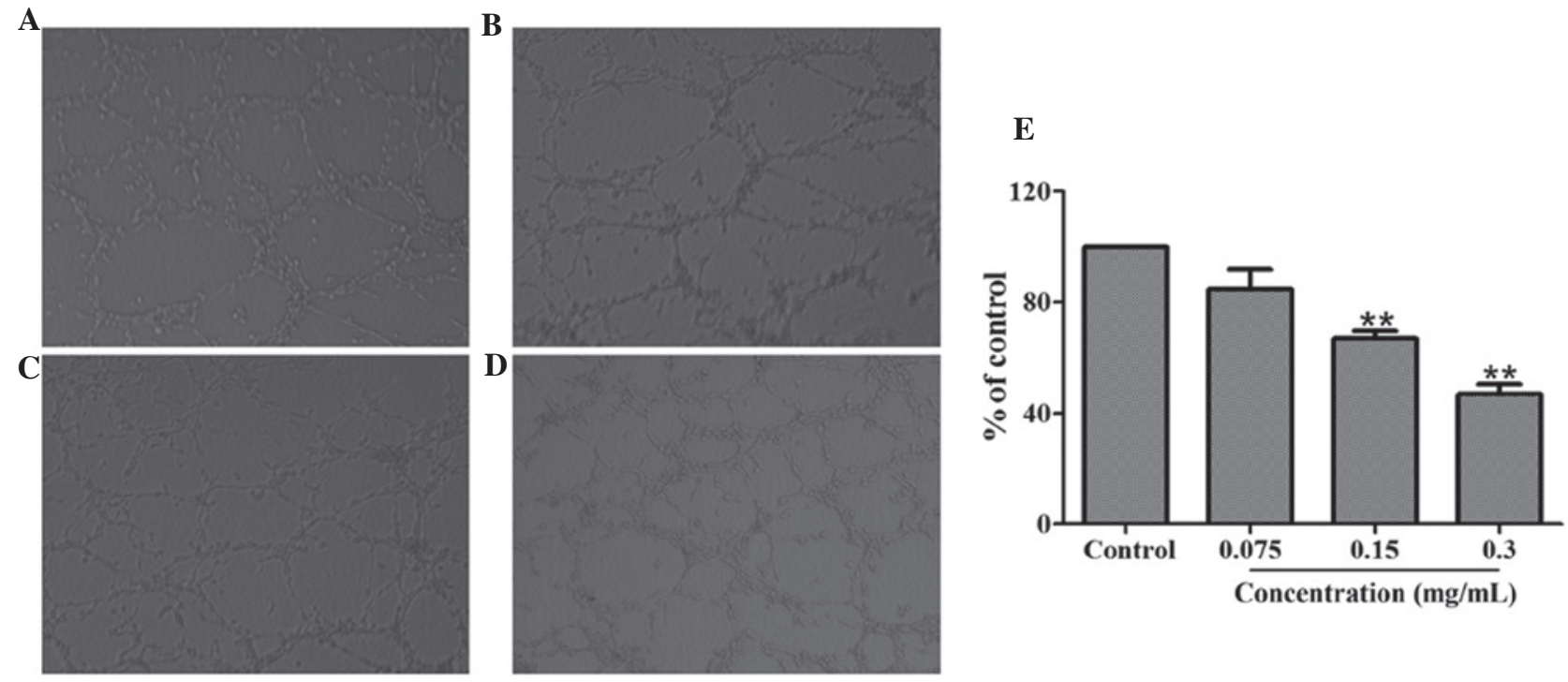

Figure 5. Eupolyphaga sinensis Walker 70\% ethanol extract inhibited angiogenesis in the TMA. (A-D) The representative images of lung tissue blood vessels in the TMA on the 5th day in (A) the untreated control group, and lung tissue vessels following $70 \%$ ethanol extract-treatment at concentrations of (B) $0.075 \mathrm{mg} / \mathrm{ml}$; (C) $0.15 \mathrm{mg} / \mathrm{ml}$ and (D) $0.3 \mathrm{mg} / \mathrm{ml}$ (scale bar, $500 \mu \mathrm{m}$ ). Vessels grew normally in the control group; vessels in the $70 \%$ ethanol extract (0.075, $0.15,0.3 \mathrm{mg} / \mathrm{ml}$ )-treated group exhibited a slow increase compared with the control group. (E) Quantification of microvessel numbers in the $70 \%$ ethanol extract treated with $0.3,0.15,0.075 \mathrm{mg} / \mathrm{ml}(\mathrm{n}=3)$. (F) Quantification of vessel length in $70 \%$ ethanol extract treated with $0.3,0.15,0.075 \mathrm{mg} / \mathrm{ml} . \mathrm{Data}$ are expressed as the mean values \pm standard error of the mean $(n=8) . ~{ }^{*} \mathrm{P}<0.05$ and ${ }^{* *} \mathrm{P}<0.01$ vs. the control group. TMA, tissue model for angiogenesis.

Eupolyphaga sinensis Walker extract on A549 human NSCLC cells and elucidated its molecular mechanisms. The results indicated that the Eupolyphaga sinensis Walker 70\% ethanol extract effectively inhibited the proliferation of A549 cells by inhibiting new blood vessel growth and blocking the KDR signaling pathway.

To extract Eupolyphaga sinensis Walker and obtain different extracts, $70 \%$ ethanol, water and $95 \%$ ethanol were 


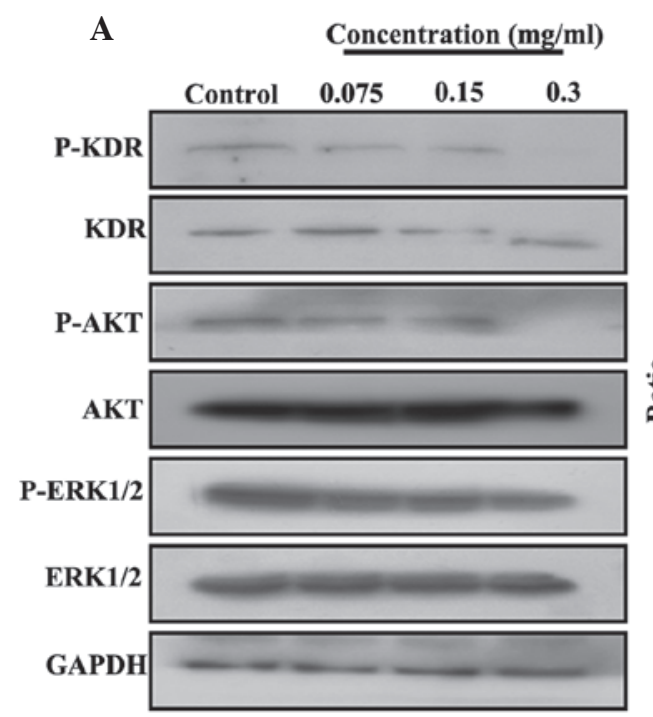

B

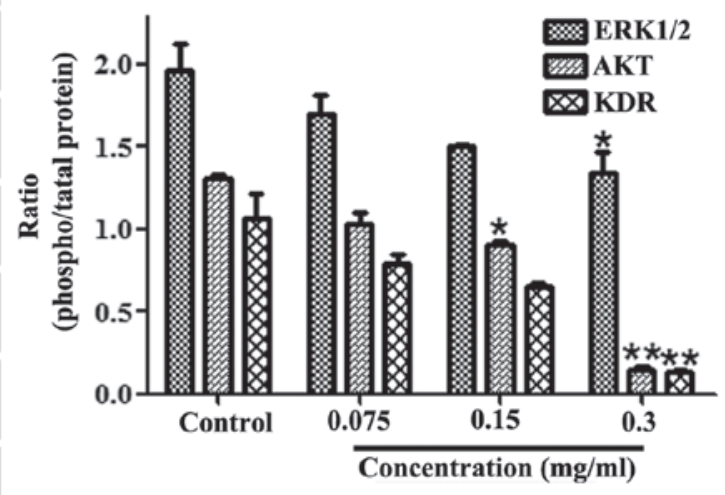

Figure 6. Eupolyphaga sinensis Walker 70\% ethanol extract regulated KDR signaling pathway proteins. (A) Eupolyphaga sinensis Walker $70 \%$ ethanol extract decreased the phosphorylation of KDR, AKT and ERK1/2. (B) Quantification of (A). " $\mathrm{P}<0.05$ and ${ }^{* *} \mathrm{P}<0.01$ compared with the control group. ERK1/2, extracellular signal-regulated kinase.

used. The MTT assay results demonstrated that Eupolyphaga sinensis Walker water extract induced weak inhibition of A549 cell proliferation while Eupolyphaga sinensis Walker $70 \%$ ethanol extract and $95 \%$ ethanol extract inhibited the growth of A549 cells in a dose-dependent manner; however the $70 \%$ ethanol extract revealed notably higher inhibition. This implied that the main antitumor activity components in Eupolyphaga sinensis Walker are of a liposoluble composition. This result is consistent with the findings of Gang-feng $\mathrm{Ge}$ (18), which demonstrated that the Eupolyphaga sinensis Walker oily extract may significantly reduce mice $\mathrm{H} 22$ tumor weight while the aqueous extract was not able to reduce tumor weight. The results of the present study may provide a basis for the extraction process that produces the effective composition of Eupolyphaga sinensis Walker extraction. The $70 \%$ ethanol extract was used for the subsequent experiments. The migration of A549 cells observed in a wound healing assay was inhibited by treatment with $70 \%$ ethanol extract in a time- and dose-dependent manner.

Due to the overexpression of VEGF in NSCLC cells, the present study aimed to investigate the antiangiogenic potential of Eupolyphaga sinensis Walker. VEGF is highly specific to endothelial cells and, in a tumor, VEGF activates the resting endothelial cells in the nearby blood vessels (21). Accompanying protease release, endothelial cells migrate towards the growth factor source, proliferate and eventually differentiate into new vessels (22). It is rational to assume that the inhibition of endothelial cell proliferation, migration and tube formation blocks the process of angiogenesis. Therefore, the associated molecular mechanisms were then examined in HUVECs. The results demonstrated that $70 \%$ ethanol extract significantly inhibited endothelial cell proliferation and migration (as determined by wound healing assay) was also evidently inhibited in a dose-dependent manner at $24 \mathrm{~h}$. It was also revealed that $70 \%$ ethanol extract was able to interrupt tube formation of HUVECs in vitro, which was in accordance with the suppression of the migration of HUVECs. Furthermore, an established tissue model for angiogenesis (TMA) was utilized, which imitated angiogenesis in vivo to evaluate the effect of $70 \%$ ethanol extract on the formation of new blood vessels at tissue level. Following treatment with $70 \%$ ethanol extract, fewer new vessels grew on the periphery of the lung tissue compared with the control group. Furthermore, in the lung tissues treated with $70 \%$ ethanol extract at $0.3,0.15,0.075 \mathrm{mg} / \mathrm{ml}$ in the TMA, vessel growth inhibition occurred in in a dose-dependent manner. These data indicated that $70 \%$ ethanol extract is able to effectively inhibit endothelial cell proliferation, migration, tube formation and reduce vessel growth in a TMA.

In NSCLC, VEGF expression is associated with increased tumor microvasculature and possibly poor prognosis (23). VEGF binds to KDR inducing its dimerization and then initiates an intracellular signal transduction cascade crucial to the process of angiogenesis (6). Therefore, whether $70 \%$ ethanol extract affected the activation of KDR was assessed in the present study. Western blot analysis demonstrated that $70 \%$ ethanol extract acted on KDR and inhibited the phosphorylation of KDR. PI3K/AKT and ERK-MAPK are two major signaling pathways that control cellular proliferation, migration, angiogenesis and apoptosis $(24,25)$. To define the signaling pathways underlying the inhibitory effects of $70 \%$ ethanol extract on the proliferation and migration of endothelial cells, the activation of AKT and ERK1/2 was examined. It was demonstrated that $70 \%$ ethanol extract downregulated the phosphorylation of AKT and ERK1/2. The results demonstrated that $70 \%$ ethanol extract inhibited A549 tumor cell growth, migration and angiogensis by downregulating the phosphorylation signaling of KDR, AKT and ERK1/2.

In conclusion, the results suggested that Eupolyphaga sinensis Walker 70\% ethanol extract inhibited endothelial cell proliferation, migration, tube formation and novel blood vessel growth in the lung tissue. In addition, Eupolyphaga sinensis Walker 70\% ethanol extract inhibited the growth of A549 cells by blocking the KDR signaling pathway. 


\section{Acknowledgements}

This study was supported by the National Natural Science Foundation of China (grant no. 81370088 and 81227802), the Fundamental Research Funds for the Central Universities of Zhuizong, the Project of Shaanxi Star of Science and Technology (grant no. 2012KJXX-06) and the Supporting Plan of Education Ministry's New Century Excellent Talents (grant no. NCET-13-0467).

\section{References}

1. Folkman J: Anti-angiogenesis: a new concept for therapy of solid tumours. Ann Surg 175: 409-416, 1972.

2. Folkman J: Angiogenesis: an organizing principle for drug discovery? Nat Rev Drug Discov 6: 273-286, 2007.

3. Folkman J: What is the evidence that tumours are angiogenesis dependent? J Natl Cancer Inst 82: 4-6, 1990.

4. Carmeliet P: Angiogenesis in life, disease and medicine. Nature 438 932-936, 2005.

5. Hanahan D and Folkman J: Patterns and emerging mechanisms of the angiogenic switch during tumorigenesis. Cell 86: 353-364, 1996.

6. Ferrara N, Gerber HP and LeCouter J: The biology of VEGF and its receptors. Nat Med 9: 669-676, 2003.

7. Kim KJ, Li B, Winer J, et al: Inhibition of vascular endothelial growth factor-induced angiogenesis suppresses tumor growth in vivo. Nature 362: 841-844, 1993.

8. Aragon-Ching A and Dahut WL: Anti-angiogenesis approach to genitourinary cancer treatment. Update Cancer Ther 3: 182-188, 2009.

9. Muñoz-Chápuli R, Quesada AR and Angel MM: Angiogenesis and signal transduction in endothelial cells. Cell Mol Life Sci 61: 2224-2243, 2004.

10. Ferrara N: Vascular endothelial growth factor: basic science and clinical progress. Endocr Rev 25: 581-611, 2004.

11. Imoto H, Osaki T, Taga S, et al: Vascular endothelial growth factor expression in non-small-cell lung cancer: prognostic significance in squamous cell carcinoma. J Thorac Cardiovasc Surg 115: 1007-1014, 1998.
12. Aragon-Ching JB and Dahut WL: Anti-angiogenesis approach to genitourinary cancer treatment. Update Cancer Ther 3: $182-188,2009$

13. Harding $\mathrm{J}$ and Burtness B: An epidermal growth factor receptor chimeric human-murine monoclonal antibody. Drugs Today (Barc) 41: 107-127, 2005.

14. Glade Bender J, Cooney EM, Kandel JJ and Yamashiro DJ: Vascular remodelling and clinical resistance to antiangiogenic cancer therapy. Drug Resist Updat 7: 289-300, 2004.

15. Ribatti D: Novel angiogenesis inhibitors: Addressing the issue of redundancy in the angiogenic signaling pathway. Cancer Treat Rev 37: 344-352, 2011.

16. Hirte HW: Novel developments in angiogenesis cancer therapy. Curr Oncol 16: 50-54, 2009.

17. Zhang CX, Tang XD and Cheng JA: The utilization and industrialization of insect resources in China. Entomological Research 38: S38-S47, 2008.

18. Ge GF, Yu CH, Yu B, Shen ZH, Zhang DL and Wu QF: Antitumor effects and chemical compositions of Eupolyphaga sinensis Walker ethanol extract. J Ethnopharmacol 141: 178-182, 2012.

19. Dai B, Zhan Y, Qi J and Zhang Y: Eupolyphaga sinensis Walker inhibits humanchronic myeloid leukemia cell K562 growth by inducing G2-M phase cell cycle arrest and targeting EGFR signaling pathway and in S180 tumor-bearing mice. Environ Toxicol Pharmacol 37: 1177-1185, 2014.

20. Dai B, Zhang Y, Zhan Y, Zhang D, Wang N and He L: A novel tissue model for angiogenesis: evaluation of inhibitors or promoters in tissue level. Sci Rep 4: 3693, 2014.

21. Ferrara N: Vascular endothelial growth factor as a target for anticancer therapy. Oncologist 9 (Suppl 1): 2-10, 2004.

22. Jain RK: Molecular regulation of vessel maturation. Nat Med 9: 685-693, 2003

23. Fontanini G, Vignati S, Boldrini L, et al: Vascular endothelial growth factor is associated with neovascularization and influences progression of non-small cell lung carcinoma. Clin Cancer Res 3: 861-865, 1997.

24. Burgering BM and Coffer PJ: Protein kinase B (c-Akt) in phosphatidylino sitol-3-OH kinase signal transduction. Nature 376: 599-602, 1995.

25. Berra E, Milanini J, Richard DE, et al: Signaling angiogenesis via $\mathrm{p} 42 / \mathrm{p} 44$ MAP kinase and hypoxia. Biochem Pharmacol 60: 1171-1178, 2000. 